\title{
Anti-diabetic Potential Properties of Two Edible Omani Wild Plants (Pteropyrum scoparium and Oxalis corniculata)
}

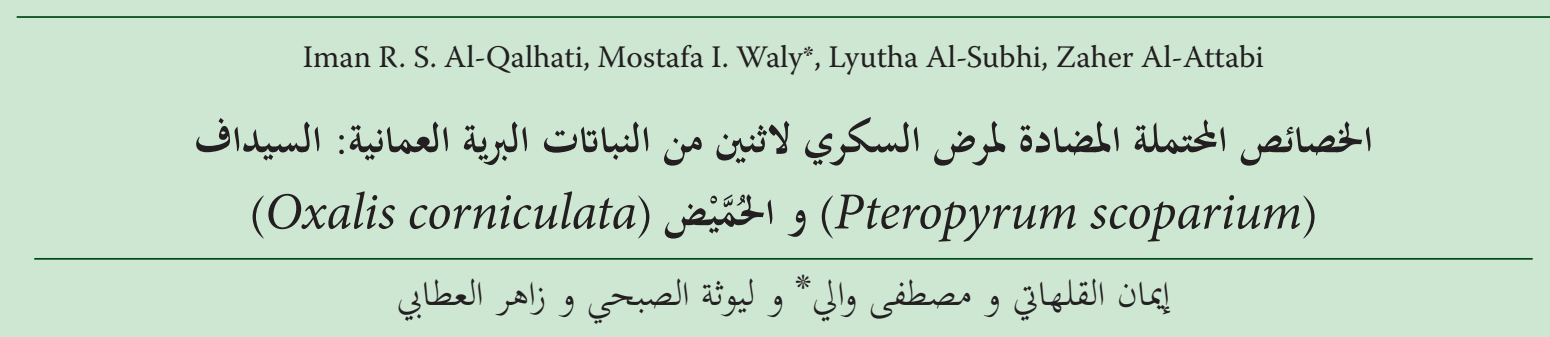

ABSTRACT. The use of plants for medicinal purposes has a long history worldwide. There is a lack of research that identifies the antidiabetic effect of edible Omani wild plants. Oxidative stress mediates the pathogenesis of diabetes and it has been suggested that natural antioxidants might be considered as an effective intervention for combating diabetes. This study aimed to assess the anti-diabetic and antioxidant potential properties of two edible Omani wild plants (Pteropyrum scoparium and Oxalis corniculata) or their mixture in streptozotocin (STZ)-induced diabetic rats. Thirty-seven male Sprague Dawley rats, weighing 250-300 g, were allocated into 5 groups: non-diabetic (9 rats/group), diabetic group (7 rats/group), and three diabetic groups that received oral feeding of either Pteropyrum scoparium, Oxalis corniculata, or their mixture (7 rats/group). Diabetes was induced by a single intraperitoneal injection dose of STZ drug, $50 \mathrm{mg} / \mathrm{kg}$ body weight. At the end of the experimental trial, after 8 weeks, all rats were fasted overnight and sacrificed; blood glucose was measured, meanwhile, pancreatic tissues were dissected and homogenized for the biochemical assessment of oxidative stress markers (glutathione, GSH, and total antioxidant capacity, TAC). STZ resulted in hyperglycemia and oxidative stress (GSH depletion and TAC impairment) in the diabetic group as compared to the non-diabetic group. Meanwhile, the concomitant treatment of diabetic groups with the two wild edible Omani plants or their mixture has shown a protective effect against the STZ-induced hyperglycemia, but with no effect on oxidative stress. It was noted that for the final body weight, the improvement was not significant. Histopathological examination of the pancreatic tissues showed that the STZ injection leads to pathological changes associated with diabetes in the pancreatic tissues of all diabetic groups. Pteropyrum scoparium and Oxalis corniculata combated the STZ-induced hyperglycemia with no effect on oxidative stress. There was no synergistic effect of Pteropyrum scoparium and Oxalis corniculata on hyperglycemia or oxidative stress.

KEYwords: Diabetes, Pteropyrum scoparium, Oxalis corniculata, Oxidative Stress

$$
\begin{aligned}
& \text { المللخص:إن استخدام النباتات للأغراض الطبية له تاريخ عريق في جميع أنخاء العالم، الا ان هناك نقص في في الأبحاث التي تحدد تأثئير النباتات البرية العمانية الصالحة }
\end{aligned}
$$

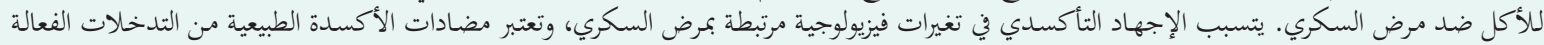

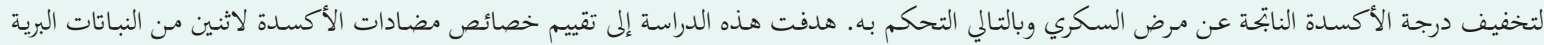

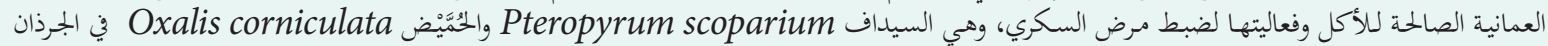

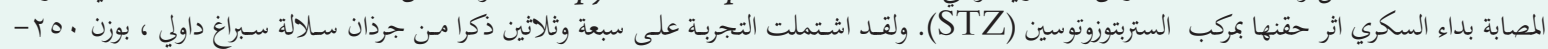

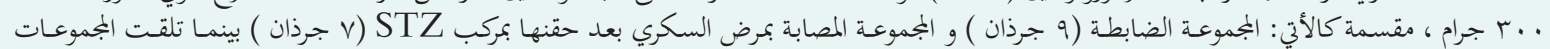

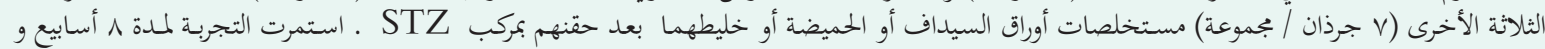

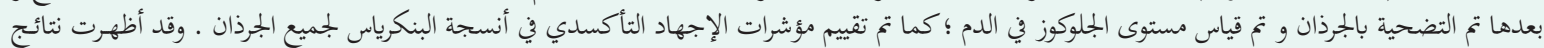

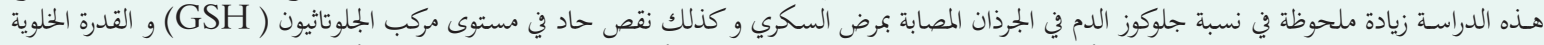

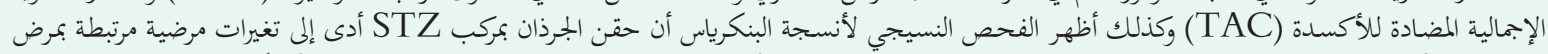

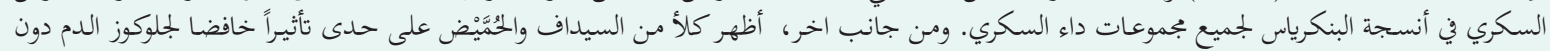

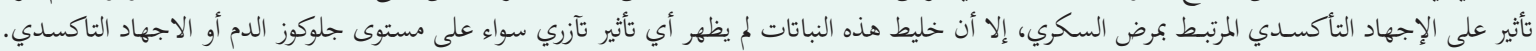

$$
\begin{aligned}
& \text { الكلمات المفتاحية: مرض السكري ، الإجهاد التأكسدي ، النباتات البرية العمانية (السيداف و المحمَّْضض). }
\end{aligned}
$$

\section{Introduction}

$\mathrm{D}$ iabetes is a major health concern due to its high incidence coupled with complications including cardiovascular problems, renal failure, and compromised immune system that in turn contribute to the increased mortality rate in adults (Waly et al.,

Mostafa I. Waly*( $(\checkmark)$ mostafa@squ.edu.om, Department of Food Science and Nutrition, College of Agricultural and Marine Sciences, Sultan Qaboos University, P. O. Box 34-123, Sultanate of Oman
2010). Oxidative stress has been involved in the etiology of various human chronic diseases including diabetes (Suresh et al., 2017), and more than 1200 plant species have been suggested for the treatment of these diseases (Krishnaiah et al., 2011). Recent studies have declared the effectiveness of some therapeutic plants and herbal preparations in the improvement of hyperglycemia (Petrovska, 2012). Edible wild plants are considered as natural therapeutic agents due to their antioxidant properties, minimum side reactions, and low cost (Petrovska, 2012). The traditional use of plants as medicine precedes 
modern medicine throughout the world (World Health Organization, 2009). According to the World Health Organization, almost $80 \%$ of the people in the world used medicinal plants for their primary health care (World Health Organization, 2009). There are many natural products that have been isolated from plants such as flavonoids, phenolics, curcuminoids, tannins, coumarins, xanthones, terpenoids, and lignans (Jeong et al., 2004). In addition, synthetic antioxidants like butylated hydroxytoluene (BHT), tert-butylhydroquinone (TBHQ), and butylated hydroxyanisole (BHA) are manufactured chemically and used in the food industry because they are more effective and cheaper than natural antioxidants (Lourenco et al., 2019). But, the use of synthetic antioxidants as food additives has raised some concerns related to their potential health problems and toxicity as TBHQ, BHA and BHT might be carcinogenic and had been banned in several western countries (Lourenco et al., 2019). Therefore, there is a lot of potential commercial use of natural antioxidants from plant extracts as an alternative for artificial synthetic ones.

There are numerous edible indigenous plant species in the Gulf Region, but there are limited studies about the health aspects of these plants in the daily food supply chain (Al-Attabi et al., 2015). Oxalis corniculata is a cosmopolitan weed spreading with a slim stem covered with rounded tipped hairs (Brown, 1989). It is commonly known as "sour grass" (Pickering et al., 2008). It grows in shady moist places and traditionally, was used for treating wounds and certain diseases (Pickering et al., 2008).

Pteropyrum scoparium grows mainly in February after the rainy season in December. It is used in the traditional food in which it is mixed with dried anchovies. The leaves were used medicinally for blood purification and the treatment of indigestion (Al-Badi, 2011). Streptozotocin (STZ) is a potent diabetic-inducing agent commonly used in rats; the STZ effect is mediated by oxidative stress in pancreatic cells (Al-Maskari et al., 2012). STZ induces diabetes in experimental animals via a mechanism that is mediated by glutathione (GSH) depletion and impairing total antioxidant capacity in pancreatic cells of rats (Al-Maskari et al., 2012). GSH is a tripeptide and acts as a part of the defense system against oxidative stress compounds like reactive oxygen and nitrogen species (Waly et al., 2015). GSH acts as antioxidants since it is a carrier for the active thiol group, and has a direct antioxidant effect through interacting with electrophiles, reactive oxygen, or nitrogen (Waly et al., 2015). Oxidative stress in pancreatic tissue is a condition under which GSH and antioxidant enzymes (glutathione peroxidase, superoxide dismutase, and catalase) are not counterbalancing ROS, and subsequently, induce pancreatic cellular damage (Unuofin and Lebelo, 2020; Matough et al., 2012). Oman region is rich in medicinal plants with antioxidant properties, therefore understanding the biological aspects of these plants in relation to oxidative-stress mediated diabetes might be considered as an effective dietary intervention in the primary prevention of diabetes. In the current study, we aimed to assess the biochemical significance of two edible Omani indigenous plants (Pteropyrum scoparium and Oxalis corniculata) using an in vivo experimental model for diabetes.

\section{Methods}

\section{Plants Preparation}

The two edible Omani wild plants, Pteropyrum scoparium and Oxalis corniculata, were freshly collected in October 2014 from two areas, Nizwa and Sur, and were identified by a specialized botanist from the Crop Sciences Department at the College of Agricultural and Marine Sciences, Sultan Qaboos University. The leaves of the collected plant were separated from the undesirable materials. Then the leaves were washed and rinsed by distilled water and dried by free zone 6-liter benchtop freeze dry system (Labconco, USA) at $-40^{\circ} \mathrm{C}$. The dried leaves were powdered by an electrical grinder (PHILIPS, HR2027). One gram of the dried powder was mixed with $50 \mathrm{~mL}$ distilled water. At the end, the mixture was stored in airtight container at $-40{ }^{\circ} \mathrm{C}$ until used for later experiments.

\section{Experimental Animals}

Thirty-seven adult Sprague Dawley male rats weighing approximately 250-300 g were used in this study. Animals were adapted to the animal house conditions for one week before starting the experiment. Animals were housed in standard laboratory room conditions at $23 \pm 2$ ${ }^{\circ} \mathrm{C}$, with a $12 \mathrm{~h}$ light/dark cycle, relative humidity of $55 \pm 10 \%$ and were maintained with free access to standard diet and tap water. The standard diet was acquired from Oman Flour Mills Company (Muscat, Oman). All the animal procedures were implemented accordingly to the "Guide for the Care and use of Laboratory Animals" published by the National Institutes of Health. An ethical approval from University Animal Research Ethics Committee was obtained (SQU/AEC/2010-11).

\section{Experimental Design and Diabetes Induction}

The thirty seven rats were randomly allocated into five groups as follow: Non-diabetic control rats $(n=9)$ that fed standard diet, Diabetic control rats $(n=7)$ that were injected with STZ and fed standard diet, Diabetic rats $(n=7)$ that were injected with STZ and fed standard diet and an oral dose of Pteropyrum scoparium extract (5 $\mathrm{ml} /$ week), Diabetic rats $(\mathrm{n}=7)$ that were injected with STZ and fed standard diet and an oral dose of Oxalis corniculata extract ( $5 \mathrm{ml} /$ week), Diabetic rats $(\mathrm{n}=7)$ that were injected with STZ and fed standard diet and an oral dose of a mixture of the extracts of both plants $(10 \mathrm{ml} /$ week). The oral dose supplementations were carried out in the same day and time on weekly basis for all groups.

The experiment was carried out for 8 weeks. Throughout the experimental period, all rats were weighed once a 
week, using a laboratory scale (Electronic Balance kern; PCB 6000-0) to the nearest gram. The allocated diabetic groups were injected with a single intra peritoneal injection of STZ (50 mg/ kg body weight) while the non-diabetic group received a single intra peritoneal injection of $0.1 \mathrm{M}$ citrate buffer solution. STZ was purchased from Sigma-Aldrich Chemical Company (product number S0130), and dissolved in a freshly prepared 0.1 M citrate buffer (pH 4.5). Diabetes was confirmed after three days of the STZ injection by measuring blood glucose. Briefly, the diabetic rats were fasted overnight and the distal part of each rat's tail was lightly snipped; the first blood drop was discarded and the second drop was absorbed by a test strip inserted in a portable glucose meter (One Touch II; Johnson \& Johnson, Milpitas, CA, USA).The blood glucose level for all rats in the diabetic groups was $\geq 200 \mathrm{mg} / \mathrm{dl}$.

\section{Animals Sacrifice and Pancreatic Tissue Homogenization}

After eight weeks of the experiment, all rats were fasted overnight and blood samples were taken from the tails to measure blood glucose level. Then all rats were anesthetized with a lethal dose of a mixture of ketamine $(1 \mathrm{mg})$, xylazine $(5 \mathrm{mg})$ and acepromazine $(0.2 \mathrm{mg})$. The pancreas was dissected and removed. Small pieces of the pancreatic tissues were placed in $10 \%$ of formalin for histopathological examination. The rest of pancreas samples $(2 \mathrm{~g})$ were homogenized in $0.1 \mathrm{M}$ phosphate buffer and centrifuged at $4000 \mathrm{rpm}$ at $4^{\circ} \mathrm{C}$ for 5 minutes. The resulting supernatants were used for protein content measurement using the Lowry's method (Lowry et al., 1951) and for biochemical measurements of glutathione and total antioxidant capacity.

\section{Biochemical Measurements}

The Glutathione (GSH) was measured using the GSH assay kit from Biovision Company (kit number; K251). The assay uses a dye that forms an adduct with glutathione which is monochlorobimane (MCB). The unbound MCB is mainly non fluorescent, while the dye fluoresces blue when bound to glutathione. This reaction is catalyzed by glutathione $\mathrm{S}$-transferase. The assay identifies both reduced and oxidized glutathione.

Total antioxidants capacity (TAC) was estimated using assay kit from Biovison Company (kit number; K274), which can measure both the small molecule antioxidants and proteins or small molecules alone in the presence of protein Mask. $\mathrm{Cu}^{2+}$ ion is converted to $\mathrm{Cu}^{+}$ by both small molecule and protein. The Protein Mask prevents $\mathrm{Cu}^{2+}$ reduction by protein, enabling the analysis of only the small molecule antioxidants. The reduced $\mathrm{Cu}^{+}$ion is chelated with a colorimetric probe giving a broad absorbance peak around $570 \mathrm{~nm}$, relative to the total antioxidant capacity.

\section{Histopathological Examination}

Pancreatic tissues saved in $10 \%$ formalin at room temperature were used to study their histological structures. The fixed specimens were dehydrated in graded ethanol, cleared in xylene and embedded in paraffin wax. Tissue blocks were sectioned into $10 \mu \mathrm{m}$ thickness using rotary microtome (Thermo Scientific STP120, Thermo Fisher Scientific UK Ltd.). The sections were stained by hematoxylin and eosin (H\&E) to examine the pancreatic tissues under conventional light microscope by a pathologist.

\section{Statistical Analysis}

The statistical analysis was performed using one-way analysis of variance (ANOVA) followed by Tukey's test using GraphPad Prism (version 5.03; GraphPad Software Inc. San Diego, CA). $P<0.05$ is considered as statistically significant. The results are expressed as means \pm Standard Error of Means (SEM).

\section{Results}

\section{Final Body Weight}

The effect of the treatment with Pteropyrum scoparium, Oxalis corniculata or their mixture on body weight in all groups is presented in Figure 1. The results exhibited that the diabetic control group showed a significant reduction in the final body weight as compared to the non-diabetic group, $P<0.05$. Diabetic groups treated with Pteropyrum scoparium, Oxalis corniculata or their mixture showed an improvement in the final body weight, although the differences were not significant $(P>0.05)$

\section{Fasting Blood Glucose Levels after Animal's Sacrifice}

Figure 2 illustrates the effect of Pteropyrum scoparium, Oxalis corniculata and their mixture on the fasting blood glucose level. STZ injection induced a significant increase in fasting blood glucose level of all diabetic groups as compared with the non-diabetic group, $P<0.05$. Feeding diabetic groups with Pteropyrum scoparium, Oxalis corniculata or their mixture positively ameliorated the elevation of blood glucose level as compared to the diabetic control group, but not significantly $(P>0.05)$.

\section{Pancreatic Tissue Antioxidants Markers}

Table 1 presented the potential effect of Pteropyrum scoparium, Oxalis corniculata or their mixture on the cellular antioxidants markers (GSH and TAC). In all diabetic groups (treated and untreated), there was a depletion in the GSH level compared to the non-diabetic control group $(P<0.05)$. There was a significant impairment of TAC level of the diabetic groups treated with the extracts of Pteropyrum scoparium, Oxalis corniculata and their mixture as compared to control non-diabetic group. 


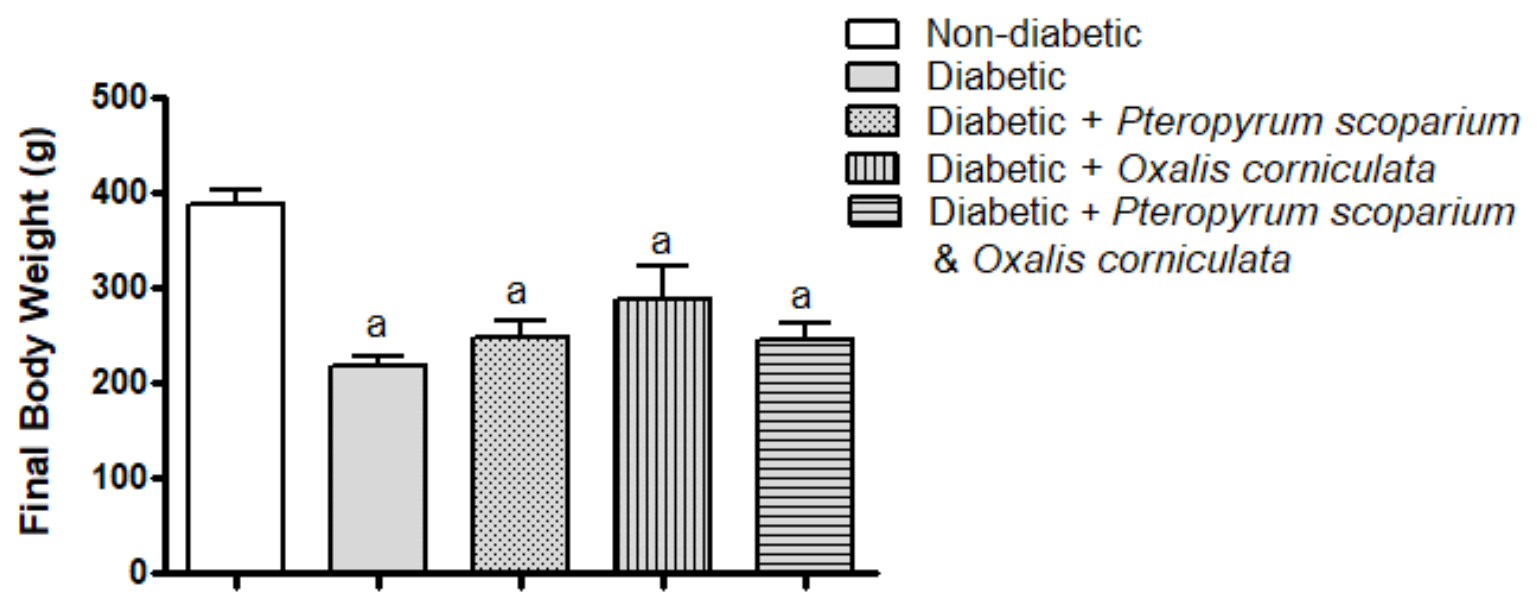

Figure 1. Final body weight in the rat groups

${ }^{a}$ All the diabetic groups had significantly lower body weight than the non-diabetic group, $\mathrm{P}<0.05$.

\section{Histopathological Examination}

Figure 3 shows the histological appearance of the pancreatic islet cells of all experimental groups. The pancreatic section from the non-diabetic control group showed the normal histological structure of pancreatic cells with increased size and cellularity of the cells (Figure 3.A). On the other hand, microscopic examination of the pancreatic sections of the diabetic control rats revealed decreased size and number of lymphocytes of $\beta$-cells of islets of Langerhans (Figure 3.B). Figures $4 \mathrm{C}$-E represents the pancreatic sections of the diabetic rats that were treated with Pteropyrum scoparium, Oxalis corniculata and their mixture, respectively. A mild to chronic lymphocytic infiltration is noted between acini in Figure 3.C; cystic dilatation of pancreatic duct was detected in Figure 3D and a congestion of pancreatic blood vessel was observed in Figure 3E.

\section{Discussion}

There is an increasing effort in searching for plants products possessing anti-diabetic activity with fewer side effects. Diabetes is a challenging metabolic disease that affects the population worldwide (Pradeepa et al., 2013). The total number of people with diabetes in the globe is estimated to increase sharply in the future (Abdul Sani et al., 2014). Several treatments were used to cure diabetes mellitus, yet these treatments have limitations and undesirable effects (Pradeepa et al., 2013). Therefore, there was an increasing effort in searching for plant products possessing anti-diabetic activity with fewer side effects (Habibuddin et al., 2008). The recent scientific studies as the traditional practices believed that the combination of many plants will be more efficient than using a single plant (Ogbonnia et al., 2008).

Few studies revealed the effect of Oxalice corniculata in diabetic animal models (Agila, 2012), while there is no study conducted with Pteropyrum scoparuim or the combination of these two plants. The present study has been undertaken to assess the effect of Pteropyrum scoparuim, Oxalice corniculata and their mixture in STZ-induced diabetic model. In the present study, the diabetic control group showed a significant decrease in the final body weight compared with non-diabetic group. The obtained findings were in agreement with a previous reported that the injection of STZ has been related with body weight loss because of the elevation in protein catabolism and muscle wasting. Moreover, the lack of insulin secretion leads to unavailability of carbohydrate which is a source of energy resulting in the observed body weight loss among the diabetic groups. This finding is consistent with what was reported earlier that administration of $50 \mathrm{mg} / \mathrm{kg}$ of STZ resulted in a significant reduction in the body weight of diabetic animals (Suresh et al., 2017; Waly et al., 2015). There were no previous studies to verify the effect of supplementation with Pteropyrum scoparium, Oxalis corniculata or their mixture on the body weight of STZ-diabetic rats. Our results showed an improvement trend in the final body weight of all three treated diabetic groups compared to the untreated diabetic control group. However, the obtained results were not significant and this may be due to the size of the dose used which might have not been enough to relief the weight loss resulting from the diabetes insult.

In our study, STZ-induced diabetic control rats showed a significantly elevation in the fasting blood glucose level when compared with the control non diabetic group, $P<0.05$. A similar result was reported earlier which stated that STZ in a dose of $50 \mathrm{mg} / \mathrm{kg}$ induced diabetes in the experimental animals (Suresh et al., 2017). Diabetes mellitus is characterized by a disturbance of glucose homeostasis and adversely affects carbohydrates, fat, and protein metabolism due to lack of insu- 


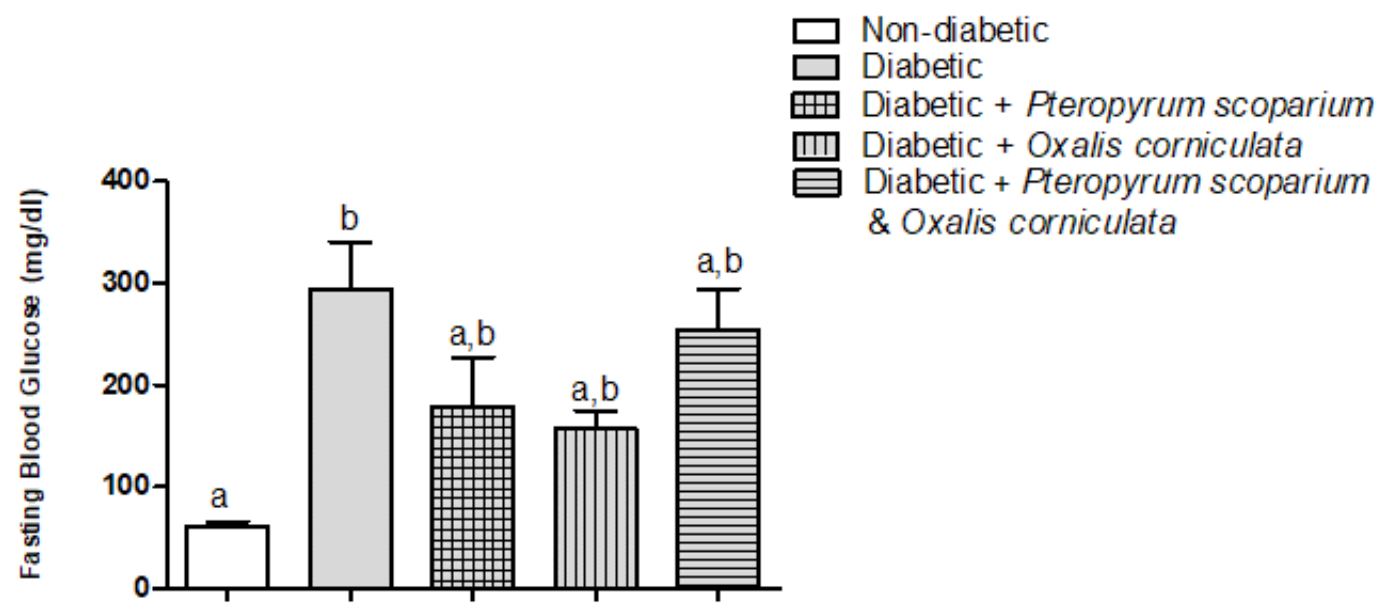

Figure 2. Fasting blood glucose measurements in the rat groups. All the diabetic groups treated with Pteropyrum scoparium, Oxalis corniculata or their mixture positively ameliorated the elevation of blood glucose level as compared to diabetic control group, but not significantly, $\mathrm{P}>0.05$

${ }^{\mathrm{a}, \mathrm{b}}$ Similar superscripts are not significantly different.

lin (Waly et al., 2015). The increase in the blood glucose level is attributed to the cytotoxic effect of STZ on pancreatic cells (Waly et al., 2015). In addition, STZ leads to destruction of $\beta$-cells of Islets of Langerhans and malfunctioning of the pancreas resulting in the blood glucose elevation (Sung et al., 2019; Agila and Kavitha, 2012).

Furthermore, our study revealed amelioration in the fasting blood glucose levels of all the treated diabetic groups. In contrast to our findings with respect to $O x$ alis corniculata, it was demonstrated that a single daily oral administration of an aqueous extract of Oxalis corniculata (100 mg/kg body weight) caused a significant reduction in the blood glucose in Alloxan-induced diabetic mice when treated for a period of ten days (do Prado et al., 2020). The results observed in our study are based on a different dose and feeding duration. On the other hand, there were no studies to compare the results obtained from treating diabetic animals with Pteropyrum scoparium or the mixture of two plants. Long term of untreated hyperglycemia in diabetes is as-
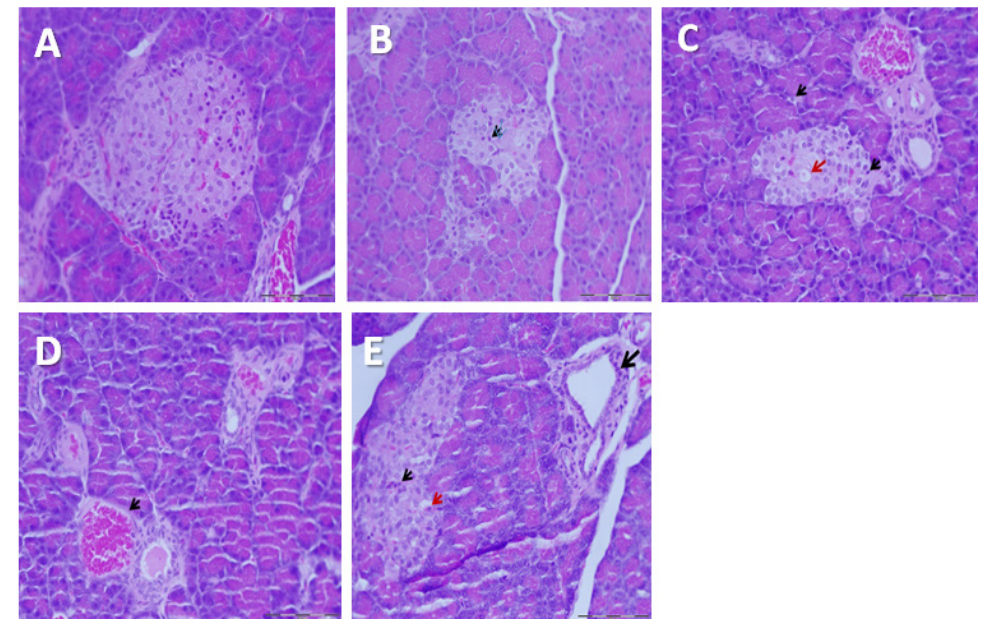

Figure 3. Histopathological examination of the pancreatic tissues of rat groups (H\&E stain $x$ 400). Section A: pancreatic tissue of the non-diabetic group consisting of acini; ducts and islets of Langerhans with no evidence of inflammation and necrosis. Section B: pancreatic tissue of the diabetic group; the islets are small (atrophic) and a few lymphocytes (black arrow) are noted. Section C: Diabetic + Pteropyrum scoparium; occasional islets show moderate chronic inflammatory cells infiltrate (black arrow) and necrosis (red arrow) with mild lymphocytic infiltration noted between acini (black arrow). Section D: Diabetic + Oxalis corniculata; show dilated and congested blood vessels (black arrow). Section E: Diabetic + Pteropyrum scoparium \& Oxalis corniculata; show moderate number of lymphocytes (black arrow), occasional single cell necrosis (red arrow) and dilated ducts (large black arrow). No improvement in the STZ-mediated pathological effects were seen in any of the three treated groups. 
Table 1. . Biochemical measurements of glutathione (GSH) and total antioxidant capacity (TAC) in the rat groups.

\begin{tabular}{lcc}
\multicolumn{1}{c}{ Group } & \multicolumn{2}{c}{ Antioxidant Marker } \\
& $\begin{array}{c}\text { GSH } \\
\text { (ng/mg protein) }\end{array}$ & $\begin{array}{c}\text { TAC } \\
\text { (ng/mg protein) }\end{array}$ \\
Non-diabetic & $1.24 \pm 0.17$ & $251.16 \pm 64.11$ \\
Diabetic & $* 0.89 \pm 0.24$ & $* 143.71 \pm 34.15$ \\
Diabetic + Pteropyrum scoparium & $0.70 \pm 0.16$ & $82.23 \pm 20.41$ \\
Diabetic + Oxalis corniculata & $0.75 \pm 0.13$ & $73.4 \pm 11.13$ \\
Diabetic + Pteropyrum scoparium \& Oxalis corniculata & $0.72 \pm 0.09$ & $68.10 \pm 5.44$
\end{tabular}

*Significantly lower than non-diabetic group, $\mathrm{P}<0.05$.

In all diabetic treated and non-treated groups there was depletion in the GSH level compared to the control non-diabetic group but this depletion was not significant $\mathrm{P}>0.05$. Meanwhile, a significant impairment of TAC level of diabetic groups treated with Pteropyrum scoparium, Oxalis corniculata or their mixture was observed as compared to control non-diabetic group.

sociated with oxidative stress generating from glucose autoxidation, protein glycation and glycoxidation leading to tissue injury and damage (do Prado et al., 2020). Induction of STZ generates $\mathrm{H} 2 \mathrm{O} 2$ and increased the production of free radicals in vitro as well as in vivo increasing the oxidative stress level (Balaji et al., 2020).

Those reactive free radical species generated by STZ contribute to DNA fragmentation and induce other damaging changes in the cells. The formation of superoxide anions could be a result of STZ action or/ and an increased activity of xanthine oxidase on mitochondria (Hassanzadeh et al., 2019). Thus high blood glucose level induces a damage to the body by many mechanisms that lastly leads to cellular stress (Jakus, 2000). In the present study, STZ-induced diabetic rats showed a depletion trend in the glutathione level. Similar results were observed in the three treated diabetic groups. Such a finding could be due to hyperglycemia which causes osmotic stress to cells by increasing the movement of glucose through polyol pathway and the production of sorbitol that consumes dihydronicotine amide adenine dinucleotide phosphate causing depletion in intracellular glutathione (Pradeepa et al., 2014).

It was reported that the best solvents of extracting the flavonoid from Oxalis corniculata are the polar solvents such as methanol and water (Al Qalhati, 2016). Moreover, the polar solvents like the ethanolic extract of Pteropyrum scoparium showed better free radical scavenging activity indicating that the Pteropyrum scoparium is a rich source of some antioxidants constituents like epicatechin-3-O-gallate (Al Qalhati, 2016). In the present study the plants extracts were aqueous-based, and the results obtained in our study showed a significant impairment of total antioxidants capacity in the three treated groups.

STZ as a diabetic insult is causing specific cytotoxicity to $\beta$-cells of the pancreas (Waly et al., 2015). It generates high level of free radicals causing DNA fragmentation of $\beta$ cells and cells necrosis which leads to decreasing the level of insulin and increasing the blood glucose level (Suresh et al., 2017). The microscopic ex- amination of the pancreatic tissue of the diabetic control group is in conformity with what was reported earlier that atrophy of $\beta$-cells of islets of Langerhans, necrosis along with cystic dilatation of pancreatic duct, reduction in cells size, decrease cellularity, and congestion of pancreatic blood vessels (Kakkar et al., 1998). These changes in pancreatic cells can be attributed to the STZ cytotoxicity causing a destruction of $\beta$-cells of the pancreas (Khattab et al., 2013). Also, this effect may be explained by generation of $\mathrm{H} 2 \mathrm{O} 2$ in the pancreatic $\beta$-cells by induction of STZ causing DNA fragmentation. In addition, the hyperglycemia stimulates the production of free radicals causing cell dysfunction and damaging the pancreatic cells (Singab et al., 2014). The microscopic examination of the pancreatic tissues of the treated diabetic groups showed no histopathological changes indicating that treatment with Pteropyrum scoparium, Oxalis corniculata or their mixture have any effect on the pancreatic tissues. This may be due to the increase in the oxidative stress (Srikanth et al., 2012).

\section{Conclusion}

In conclusion, our study demonstrated that STZ induced diabetes and oxidative stress in the experimental rat model. In addition, it indicated that Pteropyrum scoparium, Oxalis corniculata, and their mixture improved the STZ-induced hyperglycemia and the final body weight but not significantly. Neither the two plants nor their mixture has an effect on the cellular antioxidant markers or the histopathological changes in pancreatic tissues. There was no significant synergistic effect of the two plants (Pteropyrum scoparium and Oxalis corniculata) on STZ-induced diabetes and oxidative stress. Further research is needed to investigate the dose and time-dependent attributes of Pteropyrum scoparium and/or Oxalis corniculata in relation to diabetes. 


\section{References}

Abdul Sani NF, Belani LK, Pui Sin C, Abdul Rahman SNA, Das S, Zar Chi T,Yusof YAM. (2014). Effect of the combination of gelam honey and ginger on oxidative stress and metabolic profile in streptozotocin-induced diabetic Sprague-Dawley rats. Biomed Research International 2014:1-9.

Agila K. (2012). Antidiabetic, antihyperlipidaemic and antioxidant activity of Oxalis corniculata in alloxan induced diabetic mice. Journal of Natural Sciences Research 2(7): 9-17.

Al Qalhati I. 2016. Anti-diabetic Effect of Pteropyrum scoparium, Oxalis corniculata and Their Mixture in Rats, M. Sc. Thesis, Sultan Qaboos University, Oman.

Al-Attabi Z, AlMamri R, Al AbdAslam K. (2015). Antioxidant potential properties of three Wild Omani plants against hydrogen peroxide-induced oxidative stress. Canadian Journal of Clinical Nutrition 3(2): 16-22.

Al-Maskari MY, Waly MI, Ali A, Al-Shuaibi YS, Ouhtit A. (2012). Folate and vitamin B12 deficiency and hyperhomocysteinemia promote oxidative stress in adult type 2 diabetes. Nutrition 28: 23-26.

Balaji P, Madhanraj R, Rameshkumar K, Veeramanikandan V, Eyini M, Arun A, Thulasinathan B, Al Farraj DA, Elshikh MS, Alokda AM, Mahmoud AH, Tack JC, Kim HJ. (2020). Evaluation of antidiabetic activity of Pleurotus pulmonarius against streptozotocin-nicotinamide induced diabetic wistar albino rats. Saudi Journal of Biological Science 27(3): 913-924.

Brown CE. (1989). Medicinal and Other Uses of North American Plants: A Historical Survey with Special Reference to the Eastern Indian Tribes. Dover Publications Inc., pp 1-510.

do Prado FC, Vieira WF, Fernandes de Magalhaes S, Bonet IJM, Tambeli CH, Parada CA. (2020). The onset speed of hyperglycemia is important to the development of neuropathic hyperalgesia in streptozotocin-induced diabetic rats. European Journal of Neuroscience 52: 3642-3651.

Habibuddin M, Daghriri HA, Humaira T, Al Qahtani MS, Hefzi AAH. (2008). Antidiabetic effect of alcoholic extract of Caralluma sinaica L. on streptozotocin-induced diabetic rabbits. Journal of Ethnopharmacology 117(2): 215-220.

Hassanzadeh KN, Kim EY, Dryer SE. (2019). TRPC6 inactivation does not protect against diabetic kidney disease in streptozotocin (STZ)-treated Sprague-Dawley rats. FASEB Bioadvances 1(12):773-782.

Jakus V. (2000). The role of free radicals, oxidative stress and antioxidant systems in diabetic vascular disease. Bratislavske Lekarske Listy 101(10): 541-551.

Jeong SM, Kim SY, Kim DR, Jo SC, Nam KC, Ahn DU, Lee SC. (2004). Effect of heat treatment on the anti- oxidant activity of extracts from citrus peels. Journal of Agricultural Food Chemistry 52(11): 3389-93.

Kakkar R, Mantha SV, Radhi J, Prasad K, Kalra J. (1998). Increased oxidative stress in rat liver and pancreas during progression of streptozotocin-induced diabetes. Clinical Science 94(6): 623-632.

Khattab HA, Al-Amoudi NS, Al-Faleh A. (2013). Effect of Ginger, Curcumin and Their Mixture on Blood Glucose and Lipids in Diabetic Rats. Life Science Journal 10(4): 428-442.

Krishnaiah D, Sarbatly D, Nithyanandam R. (2011). A review of the antioxidant potential of medicinal plant species. Food and Bioproducts Processing 89(3): 217-233.

Lourenço SC, Moldao-Martins M, Alves VD. (2019). Antioxidants of Natural Plant Origins: From Sources to Food Industry Applications. Molecules 24(22): 1-25 (Article 4132).

Lowry OH, Rosebrough NJ, Farr AL, Randall RJ. (1951). Protein measurement with the Folin phenol reagent. Journal of Biological Chemistry 193: 265-275.

Matough FA, Budin SB, Hamid ZA, Alwahaibi N, Mohamed J. (2012). The role of oxidative stress and antioxidants in diabetic complications. Sultan Qaboos University Medical Journal 12(1): 5-18.

Al-Badi MSM.(2011). Oligomeric pronthocyandins from Petropyrum scoparium and their antioxidant properties. Sultan Qaboos University, M. Sc. Thesis, Oman.

Ogbonnia SO, Odimegwu JI, Enwuru VN. (2008). Evaluation of hypoglycaemic and hypolipidaemic effects of aqueous ethanolic extracts of Treculia africana Decne and Bryophyllum pinnatum, Lam and their mixture on streptozotocin (STZ)-induced diabetic rats. African Journal of Biotechnology 7(15): 2535-2539.

Petrovska BB. (2012). Historical review of medicinal plants' usage. Pharmacognosy Reviews 6(11): 1-5.

Pickering H, Patzelt A. (2008). Field guide to the wild plants of Oman: Royal Botanic Gardens, Oman.

Pradeepa S, Subramanian S, Kaviyarasan V. (2013). Biochemical evaluation of antidiabetic properties of Pithecellobium dulce fruits studied in streptozotocin induced experimental diabetic rats. International Journal of Herbal Medicine 1(4): 21-28.

Pradeepa S, Subramanian S, Kaviyarasan V. (2014). Antioxidant role of Pithecellobium dulce fruit pulp extract in ameliorating hyperglycemia induced oxidative stress studied in streptozotocin induced experimental diabetic rats. Journal of Pharmacy Research 8(3): 377-384.

Qihui L, Shuntian D, Xin Z, Xiaoxia Y, Zhongpei C. (2020). Protection of curcumin against streptozocin-induced pancreatic cell destruction in T2D rats. Planta Medica 86(2): 113-120. 
Singab AN, Youssef FS, Ashour ML. (2014). Medicinal plants with potential antidiabetic activity and their assessment. Med Aromat Plants 3(1): 151-156.

Srikanth M, Swetha T, Veeresh B. (2012). Phytochemistry and pharmacology of Oxalis corniculata Linn. International Journal of Pharmaceutical Sciences and Research 3(11): 1-12.

Sung Y, Jeong J, Kang RJ, Choi M, Park S, Kwon W, Lee J, Jang S, Park SJ, Kim SH, Yi J, Choi SK, Lee MH, Liu K, Dong Z, Ryoo ZY, Kim MO. (2019). Lin28a expression protects against streptozotocin-induced $\beta$-cell destruction and prevents diabetes in mice. Cell Biochemisty and Function 37(3):139-147.

Suresh S, Waly MI, Rahman MS, Guizani N, Al-Kindi MAB, Al-Issaei HKA, Al-Maskari SNM, Al-Ruqaishi BRS, Al-Salami A. Broccoli (Brassica oleracea). (2017). Reduces oxidative damage to pancreatic tissue and combats hyperglycaemia in diabetic rats. Preventive Nutrition and Food Science 22(4): 277-284.

Tripathi BK, Srivastava AK. (2006). Diabetes mellitus: Complications and therapeutics. Medical Science Monitor 12(7): RA130-147.
Unuofin JO, Lebelo SL. (2020). Antioxidant effects and mechanisms of medicinal plants and their bioactive compounds for the prevention and treatment of type 2 diabetes: An Updated Review. Oxidative Medicine Cellular Longevity 2020: 1-36 (Article 1356893).

Waly MI, Ali A, Essa MM, Al-Shuaibi Y, Al-Farsi YM. (2010). The global burden of type 2 diabetes: A review. International Journal of Biological Medical Research 1(4): 326-329.

Waly MI, Guizani N, Suresh S, Rahman MS. (2015). Ginger extract attenuates preliminary steps of streptozotocin-mediated oxidative stress in diabetic rats. International Journal of Nutrition, Pharmacology, Neurological Diseases 5: 151-158.

World Health Organization. (2009). The Use of Herbal Medicines in Primary Health Care, Technical report, 2009, pp1-66. https://apps.who.int (accessed 2 January 2020). 